\title{
Energy supply, consumption and access dynamics in Botswana
}

Article

Accepted Version

Essah, E. A. and Ofetotse, E. L. (2014) Energy supply, consumption and access dynamics in Botswana. Sustainable Cities and Society, 12. pp. 76-84. ISSN 2210-6707 doi: https://doi.org/10.1016/j.scs.2014.01.006 Available at https://centaur.reading.ac.uk/35842/

It is advisable to refer to the publisher's version if you intend to cite from the work. See Guidance on citing.

To link to this article DOI: http://dx.doi.org/10.1016/j.scs.2014.01.006

Publisher: Elsevier

All outputs in CentAUR are protected by Intellectual Property Rights law, including copyright law. Copyright and IPR is retained by the creators or other copyright holders. Terms and conditions for use of this material are defined in the End User Agreement.

\section{www.reading.ac.uk/centaur}

\section{CentAUR}

Central Archive at the University of Reading

Reading's research outputs online 


\title{
Energy supply, consumption and access dynamics in Botswana
}

\author{
Emmanuel A. Essah*a,b and Eng L Ofetotse ${ }^{\mathrm{b}}$ \\ ${ }^{a, b}$ Key Laboratory of the Three Gorges Reservoir Region's Eco-Environment, Ministry of Education, \\ Chongqing University, China \\ ${ }^{\mathrm{b}}$ School of Construction Management and Engineering, University of Reading, \\ Whiteknights, PO Box 219, Reading RG6 6AW, UK \\ *Corresponding author: e.a.essah@ reading.ac.uk, +441183788563

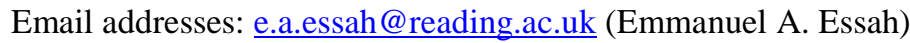 \\ e.l.ofetotse@pgr.reading.ac.uk (Eng L Ofetotse)
}

\begin{abstract}
The growing dependence on electricity for economic growth in all countries prompts the need to manage current resources for future sustainability. In today's world, greater emphasis is placed on energy conservation for energy security and for the development of every economy. However, for some countries understanding the basic drivers to such achievements is farfetched. The research presented in this paper investigates the electricity generation and access potential for Botswana. In addition detailed documentation and 13 years energy consumption and generation trends are investigated. Using questionnaires and empirical studies the energy demand for the entire nation was estimated. From the research it was established that current energy generation trends account for 38- 39\% of the country's population with access to electricity. Considering the percentage rate of sector energy demand, the proposed total installed capacity of $1332 \mathrm{MW}$, would not meet the country's energy demand at $100 \%$ access. The likely consequence of the lack of adequate supply would cumulate to significant increase of imports and/or load shedding to meet demand.
\end{abstract}

Keywords: Energy consumption, Energy supply, Energy access, Botswana

\section{Introduction}

The relationship between energy and economic development has been the centre of debate over the past 30 years with many researchers arguing that there are conflicting views as to the exact relationship between the two (e.g. Kraft and Kraft, 1978; Yu and Choi, 1985; Ang, 2008; Apergis and Payne, 2009). Nonetheless the underlying argument is that, access to affordable and reliable energy services especially electricity is a significant aid to human, social and economic development in every country. It is also closely linked to the achievement of the 
Millennium Development Goals (MDGs) (Kanagawa and Nakata, 2008; Kaygusuz, 2012; Ouedraogo, 2013). Therefore, greater emphasis is placed on energy conservation for energy security and for the development of every nation's economy as Swan and Ugursal (2009) affirm.

Intermittency of supply, increasing demand and lack of access to energy have been acknowledged to undermine energy security hence are major challenges for policymakers and organisations all over the world. These challenges became more prominent in the 1970's when energy became a major concern due to the aftermath of the oil crisis (Bhattacharyya and Timilsina, 2010). It goes without saying that underdeveloped and developing countries suffer the most when it comes to energy shortage and the lack of energy security. Notably, $95 \%$ of the 1.3 billion people in the world who do not have access to electricity and 2.6 billion people who are without clean cooking facilities reside in either sub-Saharan Africa (made up of 47 Countries most of which are either developing or underdeveloped) or developing Asia (IEA, 2012). This is a substantial percentage which will eventually impact on the economic development and growth of these countries. It is therefore pivotal that every country makes it a key objective to provide efficient and affordable access to modern energy services for all its citizens.

Although energy access is a fundamental issue for policy makers, there is no universally accepted definition of energy access. However, household (or affordable) access and grid access are often considered to be the two acceptable distinctions (IEA, 2006). Household access refers to when one is able to use electricity in the home depending on the purchasing power of a household, the cost of energy and the cost of energy using equipment. Whereas grid access is described in terms of penetration rate which refers to the proportion of a geographical area covered by the electrical grid regardless of the number of households connected (IEA, 2006). BrewHammond (2010) also states that in most cases energy access is taken to mean the ability to connect to energy, namely: electricity, Liquefied Petroleum Gas (LPG), charcoal, coal and natural gas which can either be grid connected (gc) or non-grid connected (ngc).

There are many forms of energy outlined by authors such as Brew-Hammond (2010), nevertheless, electricity is acknowledged to be one important ingredient for economic development that also improves the way of life (Winkler et al., 2011). This paper therefore focuses on electricity. Hence energy would be taken to refer to electricity and the terms would be used interchangeably. 
In this paper a comprehensive picture of the current energy system characteristics of Botswana is provided. Botswana currently depends largely on imports for its electricity supply which poses energy security instabilities. Considering the proposal for a new power station it is worth determining whether the country's energy demand would be met taking into account the losses in efficiencies as years go by. Additionally, with load shedding currently being a common occurrence, it is worth determining the current access levels of the country. Understanding these implications would assist the country in determining its energy budget hence the amount of energy that needs to be produced or imported. Furthermore, there is an increasing need for documentation regarding energy loads in Africa, with Botswana being no exception hence it is essential that detailed research is carried out to substantiate existing knowledge.

Determining the characteristics of any energy system and energy assessment is made possible through the use of energy models which are usually classified as either top down or bottom up as indicated by Swan and Ugursal (2009). There are several studies related to the application of energy models in energy assessment at national level in literature. For example Chen et al. (2008) used a statistical method to investigate national energy consumption in the Chinese residential sector. In this study real time energy consumption measurements for different appliances were investigated for 60 families over a period of a year. Yohanis et al. (2008) analysed patterns of electricity use in 27 representative households in diverse locations of Northern Ireland over a 20 month period. In this study half-hour load meters were used to measure electricity use over the 20 months period and a supporting detailed survey of householders aimed at establishing an understanding of appliance use and energy related behaviour was conducted. In another study by Widén and Wäckelgård (2010), a high resolution stochastic model which made use of occupants' schedule of living activities as well as appliance ownership and ratings was investigated to generate energy load profiles for a representative number of Swedish households. The increased application of models in developed countries is encouraging and should be something developing countries should learn from and aim to adopt. However, developing countries are limited by the lack of necessary data and required institutions which hamper the implementation of the models. Nonetheless models can be adjusted to suit the conditions of a country. For example Howells et al. (2005) applied the MARKAL model to a non electrified rural village in South Africa. Though the use of these models is not detailed in this study, the fundamental basis of work done in other countries using such models and methods is worth noting. In 
this study a statistical method has been used to investigate energy consumption of the Botswana residential sector and consequently that of the whole country.

The paper is organised as follow: Section 2 gives an outlook of Botswana's energy supply. Section 3 gives an overview of the country's energy consumption and access situation. Section 4 outlines the methodology adapted for the research. Section 5 gives the research analysis and results while Section 6 presents the concluding remarks.

\section{Energy Supply Outlook of Botswana}

The Republic of Botswana is a landlocked country (Fig. 1) with a total land area of $581,730 \mathrm{~km}^{2}(\mathrm{CSO}, 2011)$. The country generates its electricity primarily from coal largely because of its abundance and alleged cost effectiveness (Fagbenle, 2001). Although there are abundant coal reserves (estimated at 212-billion tonnes) found in different parts of the country (Fagbenle, 2001), only those in Morupule Colliery (estimated at 70billion tonnes) located between Palapye and Serowe villages (see Fig. 1) are currently being mined for electricity generation. The Morupule Colliery supplies coal to the Morupule A Power Station (adjacent to the Morupule Colliery) which is the only power station currently operating in Botswana.

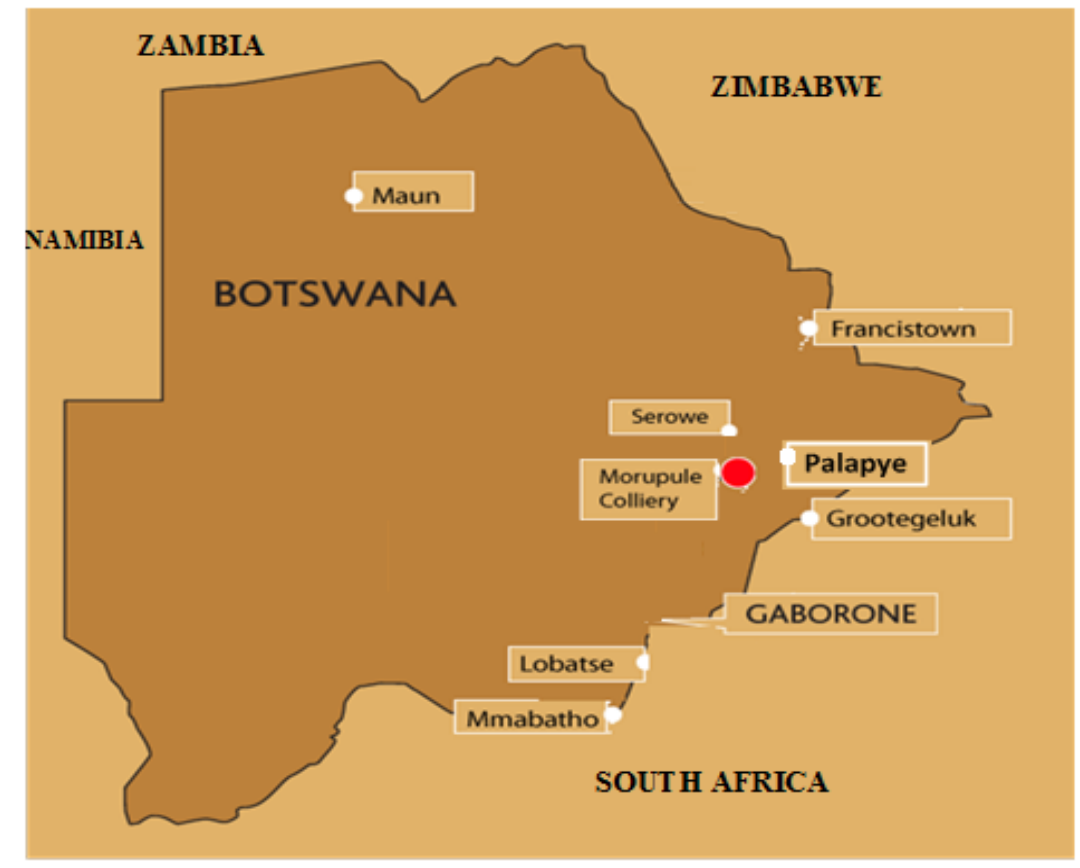

Fig. 1. Map of Botswana and its neighbouring countries with an inset of Morupule Colliery (Source: Asenjoenergy, 2008) 


\subsection{Morupule A power station}

The Morupule A power station is a coal fired station with steam turbine driven thermal plants owned and operated by the Botswana Power Corporation (BPC) (BPC, 2011). The BPC is a government owned company operating without any external competition therefore acting as a monopoly (Ofetotse and Essah, 2012).

The coal-fired power station was commissioned in 1986 with an installed capacity of 132 MW and an operational capacity of 120 MW (BPC, 2011), i.e. 91\% conversion efficiency. As it would be expected this capacity decreased as years went by, reducing the station's dependable operational capacity to $100 \mathrm{MW}$ (76\%) as stated in BPC (2011). The power station generates on average 27\% (based on a 13 year input, see Table 1) of the country's total energy supply with the rest of the country's requirements obtained through imports. In 2012, the Morupule power station supplied a little under 7\% (a decrease from 12\% in 2011 and $15 \%$ in 2010) of the country's supply while $70 \%$ was sourced from Eskom in South Africa and $23 \%$ from other providers such as Nampower in Namibia, Electricidade de Mocambique (EDM) in Mozambique and Societe Nationale d'Electricide (SNEL) in Democratic Republic of Congo (BPC, 2012).

The decrease in generation was attributed to a decrease in operational capacity, which was 40 MW in 2011 compared to its normal $100 \mathrm{MW}$ (BPC, 2011). Although it was not stated as to what the operational capacity in 2012 was, it is clear that it had reduced from the 2011 value due to even lower national generation shown in Table 1 and Fig. 2. In addition, the Morupule A Power Station (commissioned in 1986) is nearing the last years of its useful life which was anticipated to be between 25-30 years from the year it was commissioned (BPC, 2010). This aging trend has significant implications which are reflective in the reduced operational capacity hence reduced electricity generation. In light of all these causes of low generation the role that a second power station would play in the energy supply system of Botswana cannot be over emphasised.

After a residual life assessment was carried out on the plant in 2009 it was suggested that if extensive refurbishment can be carried out, the remaining useful life of Morupule A power station can be extended by another 15 years (BPC,2010), this however remains to be substantiated. There have been on-going refurbishments on the power station since 2010 in efforts to restore the power station's dependable capacity to $100 \mathrm{MW}$. The refurbishments which are said to be carried out in phases (BPC, 2010) have also contributed to 
the decline in plant availability hence a decline in energy generation which has led to BPC resorting to load shedding and electricity rationing in efforts to address the acute power shortages. Consequently, there has been rolling power outages many of which last for several hours spreading across the country.

\subsection{Energy supply trends}

The main aim of the Botswana's national energy policy is to provide affordable, environmentally friendly and sustainable energy services in order to promote sustainable social and economic development (National energy policy for Botswana, 2010). To meet this aim, there are a number of defined objectives that include the following;

- Increasing access to affordable energy services for all sectors of the economy and all members of the population especially the poor.

- Improving energy security through diversity in supply. This involves the promotion of more use of locally available sources such as coal and alternative energy sources (such as solar energy) instead of importing electricity.

Although the goals set within the policy are important, they are meaningless if not implemented therefore, policies should not just be abstract but should put in action plans to eradicate the lack of access to electricity in Botswana. This means there should be clearly defined and documented targets to improve the supply levels in the country. At present there is shortage of such documentation hence the need for research that would provide information for documentation or augment the existing ones.

As mentioned in previous sections, Botswana relies heavily on imported power which is a threat to security of supply. This Section therefore gives an overview of the energy generation and supply trends of Botswana based on a 13 year data input obtained from the only existing BPC documentation. The thirteen year period was used to enable the development of a credible understanding of the trends in energy generation and supply in Botswana as well as to generate substantial data for analysis.

In the context of this paper energy generation is the process of producing energy from a source while energy supply is the delivery of energy to the point of consumption. Table 1 and Fig. 2 give details of electricity 
generation and supply trends for years 2000 to 2012. Energy from national generation, imports, station usage, losses and exports were used to compute the total energy generation and the total energy available for supply using Equation 1.

$\mathrm{E}_{a}=\mathrm{E}_{\mathrm{tot}}-\left(\mathrm{S}_{\mathrm{u}}+\mathrm{L}_{\mathrm{dt}}+\mathrm{E}_{\mathrm{e}}\right)$

Where

$\mathbf{E}_{\mathbf{a}}=$ Total energy available for supply

$\mathbf{E}_{\text {tot }}=$ the total energy the country generates from both imports and national generation

$\mathbf{S}_{\mathbf{u}}=$ Station usage (energy used by the power station to generate electricity)

$\mathbf{L}_{\mathrm{dt}}=$ losses (due to distribution and transmission as documented by BPC)

$\mathbf{E}_{\mathrm{e}}=$ energy exported

It would be noted that though Equation 1 includes exports, Botswana does not currently export any power hence exports are not included in both Table 1 and Fig. 2. The data used for Fig. 2 and Table 1 was obtained from the BPC annual reports (BPC, 2010; BPC, 2011 and BPC, 2012).

In Fig. 2, it can be seen that national generation was declining over the 13 year period. In 2000 national generation was $51 \%$ of total supply (i.e. $1027 \mathrm{GWh}$ ), this value declined by an average $10 \%$ (i.e. $65 \mathrm{GWh}$ ) over the 13 year period reducing to $7 \%$ of total generation (i.e. $250 \mathrm{GWh}$ ) by 2012 . This decline can be attributed to reasons mentioned in Section 2.1. To compensate for this, Botswana had to import more energy which is indicated by the continual rise in imports. In 2000 imported energy was $968 \mathrm{GWh}$ (which is $49 \%$ of total supply). This value rose by an average $11 \%$ (i.e. $200 \mathrm{GWh}$ ) over the 13 year period reaching $3371 \mathrm{GWh}(93 \%$ of total supply) in 2012. This demonstrates the extent to which the country's reliance on imports has increased over the years which is a big threat to the nation's energy security. 
Table 1: Botswana's electricity generation and supply for 2000-2012

\begin{tabular}{|c|c|c|c|c|c|c|}
\hline YEAR & $\begin{array}{c}\text { National generation } \\
(\text { GWh })\end{array}$ & $\begin{array}{l}\text { Imports } \\
\text { (GWh) }\end{array}$ & $\begin{array}{c}\text { Total } \\
\text { generation } \\
(\mathbf{G W h})\end{array}$ & $\begin{array}{c}\text { Station } \\
\text { usage } \\
\text { (GWh) }\end{array}$ & $\begin{array}{l}\text { Losses } \\
(\text { GWh })\end{array}$ & $\begin{array}{l}\text { Electricity available } \\
\text { for supply (GWh) }\end{array}$ \\
\hline 2000 & 1027 & 968 & 1995 & 115 & 209 & 1671 \\
\hline 2001 & 1035 & 1123 & 2158 & 115 & 200 & 1843 \\
\hline 2002 & 1044 & 1242 & 2286 & 116 & 215 & 1955 \\
\hline 2003 & 936 & 1606 & 2541 & 106 & 285 & 2150 \\
\hline 2004 & 823 & 1915 & 2738 & 96 & 276 & 2366 \\
\hline 2005 & 942 & 1898 & 2840 & 109 & 315 & 2416 \\
\hline 2006 & 977 & 2050 & 3028 & 111 & 290 & 2627 \\
\hline 2007 & 822 & 2394 & 3215 & 95 & 343 & 2777 \\
\hline 2008 & 697 & 2585 & 3282 & 67 & 327 & 2888 \\
\hline 2009 & 621 & 2749 & 3369 & 71 & 381 & 2917 \\
\hline 2010 & 532 & 2985 & 3517 & 75 & 333 & 3109 \\
\hline 2011 & 437 & 3180 & 3617 & 66 & 434 & 3118 \\
\hline 2012 & 250 & 3371 & 3621 & 30 & 393 & 3198 \\
\hline
\end{tabular}

Source: Annual reports (BPC, 2010; 2011; 2012)

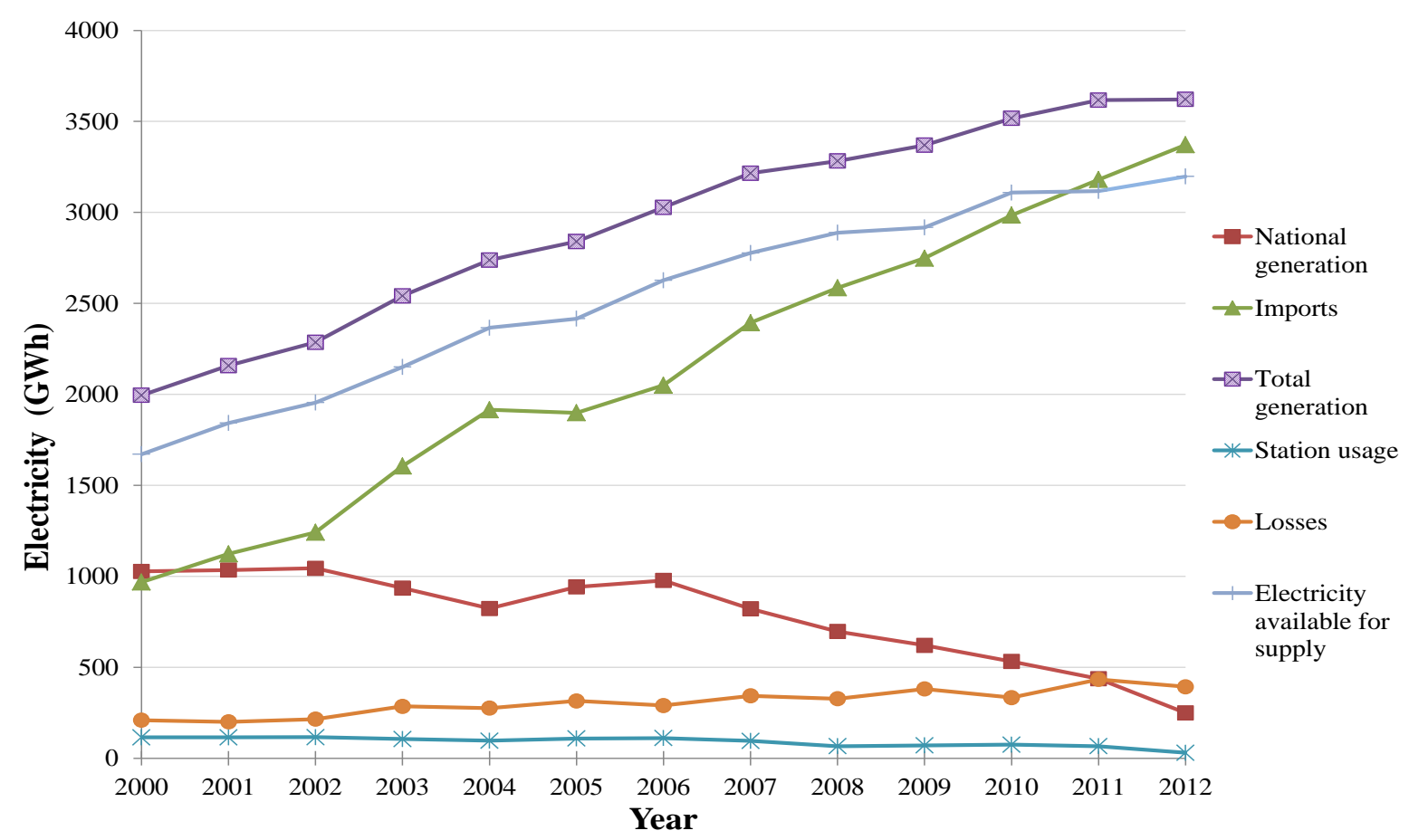

Fig. 2. Electricity generation trends with respect to different variable (Source: BPC, 2010;2011;2012) 
Total energy generation (Fig. 2) has increased over the 13 year period, but with an increasing proportion of energy being imported and with national generation decreasing. In 2000 total generation was 1995 GWh, the value increased steadily every year to reach $3621 \mathrm{GWh}$ in 2012 . Station usage which is energy used by the power station to generate electricity was declining over the 13 years. However, the station usage remained at an average of $11 \%$ of the national generation throughout the 13 years. The decline in energy used by the station therefore correlates with the decline in national generation.

Processing, delivery and utilisation of electricity involve losses, which can be technical or non-technical. Technical losses occur during transmission and distribution and involve substation, transformer and line related losses (Navani et al., 2003). While non-technical losses occur as a result of vandalism, theft, metering inaccuracies, unmetered energy (Navani et al., 2003). It has therefore been revealed that non-technical losses are difficult to compute compared to technical losses mainly because technical losses are internal to the supply system while non-technical losses are external (Navani et al. 2003; Smith, 2004). Therefore in this study only technical losses (transmission and distribution) will be taken into consideration. Although it may be the case that losses documented in Botswana are accounting for non- technical losses, this cannot be proven. In the case of Botswana, losses arise due to the fact that there is one electrical power station that has to transmit electricity over long distances to reach places far from the source. This is also compounded by the importation of electricity from South Africa and other neighbouring countries. Losses due to transmission and distribution increased at an average of $6 \%$ over the 13 years with 2011 recording the highest losses (434 GWh) since 2000.

Energy available for supply (energy delivered to the end users) is the most important factor of all the factors shown Table 1 and Fig. 2 because it not only provides revenue to a power station but it is the amount of energy available for use by end users. It is therefore important that losses are kept to a minimum so that more power can reach end-users. In Botswana, energy available for supply increased by $6 \%$ (132 GWh) on average over the years. Although a steady increase in energy available for supply has been noted, Botswana does not meet all its requirements which are evidenced by constant blackouts that the country is currently facing. These blackouts are in efforts to ration energy in efforts to reduce demand especially during morning and evening peaks. In Botswana each city has its own load shedding schedule hence the blackouts can be said to be localised. 
From Fig. 2, it is clear that Botswana relies heavily on imports because at its declining capacity the Morupule A power station is failing to generate even half of what is used in the country. Relying on imports compromises security of supply since the country's main electricity provider Eskom (from South Africa) is also currently struggling to meet South Africa's national demands and has had to cut back on supplies to Botswana (Eskom, 2011). In addition, Eskom planned to completely end electricity supplies to Botswana by end of 2012 in anticipation of the new proposed power station (see Section 2.3) being in operation (Mining-technology, 2012). However, the proposed power station was not in operation at the end of 2012 and is still not in operation in 2013. Therefore the country has had to negotiate a new 300 MW contract with South Africa. Since January 2013, the country has been receiving $100 \mathrm{MW}$ on an agreed and guaranteed basis and another $200 \mathrm{MW}$ which is not guaranteed, meaning it is provided depending on South Africa's own needs. The 200 MW deal expired in July 2013, while the 100 MW deal will end in 2015 (Mguni and Benza, 2013). With South Africa cutting back on its supplies to Botswana, the security of energy supply is in question hence the need for the country to develop a strategy to achieve self-sufficiency and eliminate/reduce over reliance on imports.

\subsection{Morupule B power station}

To reduce overdependence on imports and improve security of supply, the country proposed in their strategic plan, to build two new 4 x 150 MW units Circulating Fluidized Bed (CFB) Power plants (Morupule B power station) adjacent to the existing Morupule A power station (within the Morupule colliery). The new power plants were scheduled to be built in two phases; with phase I having a capacity of $600 \mathrm{MW}$ and phase II commissioning another $600 \mathrm{MW}$ (BPC, 2011). Phase I was scheduled to begin full operation (all four units) in the last quarter (i.e. from October) of 2012 (BPC, 2012) while phase II was schedule to be in operation at the end of 2013. The completion of phase II was expected to bring the total installed capacity of Botswana to 1,332 MW (more than a ten-fold increase on the current installed capacity). The increased installed capacity was anticipated to meet all the country's energy needs with the potential for obtaining foreign exchange through export of surplus generation (National energy policy for Botswana, 2010). Although this is encouraging, estimates by Ofetotse and Essah (2012) suggests that it is overly ambitious.

Almost a year after the proposed completion target date, the first phase of the station is still not in full operation. It is stated that the one unit (150 MW) of the station which began operation in 2012 had to be closed down due to mechanical faults and the other two $(2 * 150 \mathrm{MW})$ are undergoing technical repairs while one $(150 \mathrm{MW})$ is still 
under construction (Mguni and Benza, 2013). According to Mguni and Benza, (2013) the failure to attaining completion were attributed to the following:

- 2011 truckers' strike in South Africa that delayed movement of equipment from Durban to the construction site.

- $\quad$ Bad weather in 2010-2012 and typhoons at sea close to South Africa

- Problems encountered during commissioning of the initial $150 \mathrm{MW}$, such as blockages and steam tube leaks on boilers.

- The contractor's non-compliance with the Safety, Health and Environmental (SHE) standards and technical integrity in 2012 that resulted in three fatalities

With all these challenges the plans and strategies for Botswana to obtain self-sufficiency is currently farfetched but not impossible.

\section{Energy Consumption}

In the context of this paper energy consumption is the energy disseminated to different sectors of the economy while energy demand is the energy that the end users require to meet all their needs. Consumption is therefore the use of what is available while demand is what should actually be supplied.

Table 2, Fig. 3 and Fig. 4 show the changing levels of energy consumption by sector as well as the share of consumption by each sector compared to the total consumption between years 2000 and 2012. The mining sector has had the highest energy consumption over the 13 year period although its percentage share began to decline substantially from 2006, declining to 34\% (1086 GWh) in 2012 (see Table 2). Energy consumption of the sector increased by an average of $3 \%$ over the years, increasing from $760 \mathrm{GWh}$ in 2000 to $1086 \mathrm{GWh}$ in 2012. Up until 2007, the commercial sector ranked second in energy consumption (see Table 2 and Fig. 4). The sector consumption increased gradually over the 13 years, increasing from $492 \mathrm{GWh}$ in 2000 to $910 \mathrm{GWh}$ in 2012. Since 2007 the domestic sector ranked second in energy consumption with exceptions of 2010 and 2012 where there seems to be a flattening of growth. Over the 13 year period the domestic sector consumption increased progressively by $10 \%$ (i.e. $50 \mathrm{GWh}$ ) on average reaching $879 \mathrm{GWh}$ in 2012 compared to $280 \mathrm{GWh}$ in 2000. The government sector had the lowest energy consumption compared to other sectors over the 13 year 
period. Its consumption increased steadily by $8 \%(15 \mathrm{GWh})$ over the years to reach $239 \mathrm{GWh}(10 \%$ of total consumption) in 2012 compared to $139 \mathrm{GWh}$ (8\% of total consumption) in 2000 . It must be noted that percentage shares were calculated from known values of electricity consumption by sector that is quoted in BPC documentation (Table 2).

Table 2: Electricity consumption and percentage of total consumption by sector

\begin{tabular}{|c|c|c|c|c|c|c|c|c|c|}
\hline \multirow[t]{2}{*}{ Year } & \multicolumn{5}{|c|}{ Electricity consumption by sector (GWh) } & \multicolumn{4}{|c|}{ Shares of electricity consumption by sector $(\%)$} \\
\hline & Mining & Commercial & Domestic & Government & Total & Mining & Commercial & Domestic & Government \\
\hline 2000 & 760 & 492 & 280 & 139 & 1671 & 45.5 & 29.4 & 16.8 & 8.3 \\
\hline 2001 & 899 & 462 & 334 & 147 & 1843 & 48.8 & 25.1 & 18.1 & 8.0 \\
\hline 2002 & 920 & 478 & 371 & 187 & 1955 & 47.0 & 24.5 & 19.0 & 9.5 \\
\hline 2003 & 1001 & 533 & 420 & 196 & 2150 & 46.6 & 24.8 & 19.5 & 9.1 \\
\hline 2004 & 1077 & 573 & 489 & 227 & 2366 & 45.5 & 24.2 & 20.7 & 9.6 \\
\hline 2005 & 1047 & 613 & 539 & 217 & 2416 & 43.3 & 25.4 & 22.3 & 9.0 \\
\hline 2006 & 1184 & 631 & 584 & 227 & 2626 & 45.1 & 24.0 & 22.3 & 8.6 \\
\hline 2007 & 1199 & 634 & 682 & 262 & 2777 & 43.2 & 22.8 & 24.6 & 9.4 \\
\hline 2008 & 1186 & 684 & 745 & 274 & 2889 & 41.0 & 23.7 & 25.8 & 9.5 \\
\hline 2009 & 1123 & 735 & 769 & 290 & 2917 & 38.5 & 25.2 & 26.4 & 10.0 \\
\hline 2010 & 1141 & 831 & 829 & 308 & 3109 & 36.7 & 26.7 & 26.7 & 9.9 \\
\hline 2011 & 1117 & 820 & 873 & 308 & 3118 & 35.8 & 26.3 & 28.0 & 9.9 \\
\hline 2012 & 1086 & 910 & 879 & 323 & 3198 & 34.0 & 28.5 & 27.5 & 10.0 \\
\hline
\end{tabular}

(Source: BPC, 2010; 2011; 2012) 


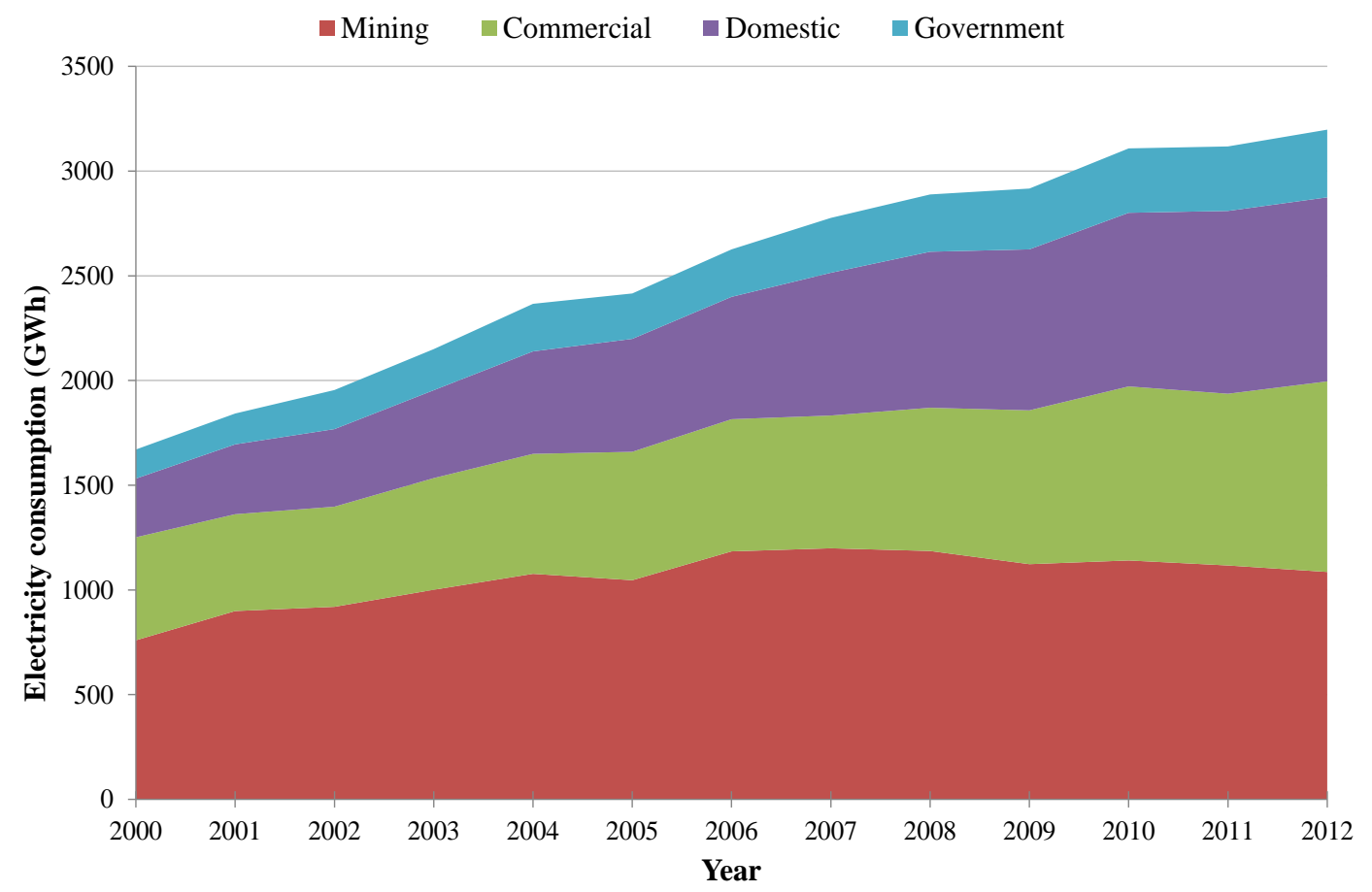

Fig. 3: Botswana final energy consumption trends by sector 2000-2012 (Source: BPC, 2010; 2011; 2012)

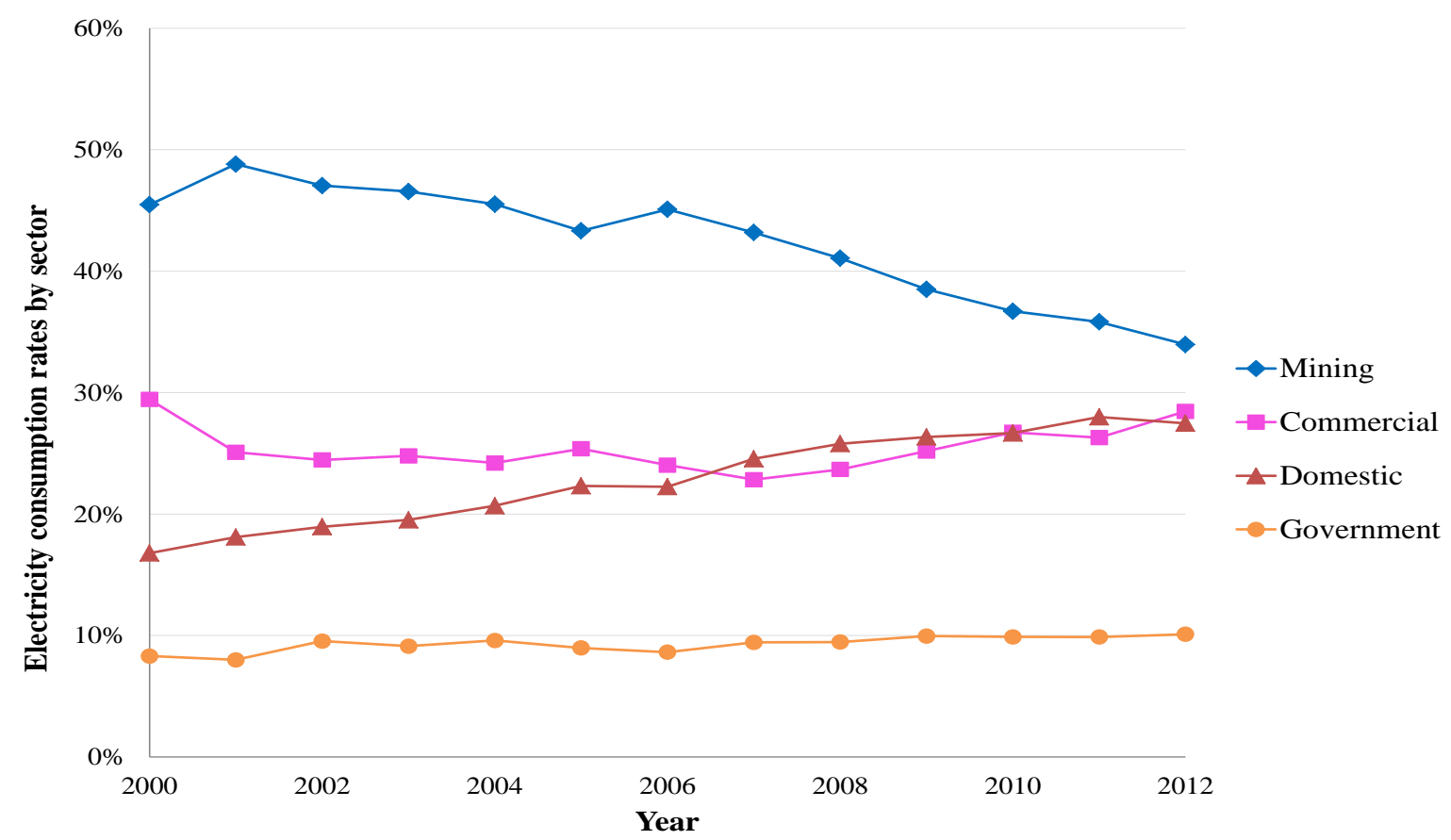

Fig. 4: Sectors' electricity consumption as a percentage of total consumption from 2000-2012

Of all the sectors the domestic sector had the highest growth in energy consumption. It is also the only sector that has not had a significant decline in energy consumption over the 13 years, instead there has been a steady increase in the energy consumption (Fig. 3 and Fig. 4). For this reason the sector's energy consumption requires further investigation in efforts to manage energy consumption and promote energy conservation. 


\subsection{Energy access}

The constant load shedding that the country is currently experiencing shows that current energy demand is not met by current national generation and imports. BPC (2012) indicates that $49 \%$ of people have access to electricity as at 2012, an increase from $43 \%$ in 2011 which shows that the infrastructure does not provide to all citizens. Therefore, if the country aims to increase the electricity grid then demand will increase significantly even with efficiency measures. This is a challenge that has to be taken into consideration when generation capacity is being expanded. Another challenge that is currently facing the country is that there are conflicting views on energy access levels documented within documentation. A case in point is that while BPC (2012) quotes $49 \%$ access as at 2012, the National energy policy for Botswana (2010) quotes 58\% (as at 2010) accessibility. In addition the national energy policy for Botswana (2010) quotes the rural electrification figure as at 2010 to be $52.3 \%$ while the BPC (2011) quotes the figure of 50.8\% accessibility for 2010 and $53 \%$ for 2011 . This therefore raises questions as to the accuracy of the figures quoted; an argument that is also echoed by Ofetotse and Essah (2012). The accurate estimation of access levels is important in determining the energy budget for the country. As a result it is necessary that to meet the growing demand for electricity and for energy planning purposes, the actual access and energy demand values be investigated and accurately documented.

\subsection{The domestic sector energy demand}

The domestic sector has been identified as a substantial consumer of energy in many countries around the world. Values quoted are within a range of $16-50 \%$ of the total energy demand in different countries and average to 30\% worldwide (Saidur et al., 2007). Swan and Ugursal (2009) have thrown light on the fact that there are numerous fundamental parameters that influence the levels of energy consumption in the domestic sectors. These have been identified to include; understanding the effect of climate change, high energy prices, and energy supply/demand, on the consumption characteristics of the domestic sector (Swan and Ugursal, 2009). The detailed understanding of the significance of these parameters has been acknowledged to contribute to demand side management (DSM) strategies through the promotion of conservation, efficiency, technology implementation and use of alternative energy sources as Swan and Ugursal (2009) continues to state. Therefore, the comprehensive understanding of the basis of energy consumption in the domestic sector is still an area of significant research. 
In this study, data collected from the domestic sector is used to inform other sectors and to compute the energy budget of the whole country. The growing trends of the domestic sector demand are also estimated and can be used to inform the trends of the other sectors. In Botswana there is a general lack of documentation, therefore this study is an initial study to attempt to estimate the energy consumption of the domestic sector and eventually other sectors.

\section{Methodology}

To address the concerns raised in this paper, the electrical energy demand has been determined using two main approaches; questionnaire survey and empirical study. A questionnaire survey was developed and used to collect data that eventually formed the basis of the empirical study. The data was collated from the second half of 2011 to the end of the first quarter of 2012. The results of the empirical study were then extrapolated to obtain an estimate of the energy requirements of other sectors as categorised within Botswana (see Section 3) hence the requirement of the whole country. 520 questionnaires were administered to different households and 415 responses were received. Twelve questionnaires were discarded because of inaccurate completion and 1 omitted to ensure equal number of questionnaires per income category. The final analysis was based on $402(77.3 \%)$ fully completed responses. The final responses were categorised under three major sub-income brackets; low, medium and high. This categorisation was based on the size, lease and mortgage of households as set by the

Botswana Housing Corporation (BHC). Therefore, respondents were asked to give details of the size of their property (in terms of number of rooms and floor footprint), tenature and lease/mortgage price.

Generally, larger houses are more expensive, while medium sized houses are of average cost and small ones are of the lowest cost in terms of both rent and mortgage (BHC, 2009). Although house prices are locational, categorisation of households into high, medium and low income is dependent on the average disposable income and the house prices in an area. Disposable income and property prices in cities and towns are higher than in rural areas because of differences in costs of living. Therefore, even though a high income earner in a city may earns more than a high income earner in a rural area they are still high income earners in their respective place of residence. Consequently, even though a high income house in a city may be more expensive that one in a rural area it is still a high income house in its respective area. 
It is a requirement of the Corporation that a person wishing to rent a house should have a net income that is $30 \%$ more than the prospective rented accommodation (BHC, 2009). Therefore, the size of household rented also gives an indication of the income bracket of the household. In addition to the BHC classification, the CSO (2010) states that $38 \%$ of households in Botswana are low income while $46 \%$ are middle income and the remaining $16 \%$ are high income. This categorisation has been used to derive multipliers for the three income categories and have been integrated into Equation 3. The 2011 census results indicated that there are 2,038,228 people living in 555, 395 households in Botswana. Therefore the number of households per category were determined and integrated into Table 3. The responses from the questionnaires shows a normal distribution hence the assumption that it is representative of the entire population.

\subsection{Energy Use}

The use of electricity in domestic buildings is determined by several factors that include the season of the year (e.g. cold or hot season), dwelling size, number of occupants, type and number of electrical appliances in the property and the use of the appliances by the building occupants (based on lifestyle/behaviour patterns). Efficiency of appliances also influences their energy consumption. Therefore consumption would vary per hour, weekday, weekend, months and years. This is equally different from one dwelling to other.

For this study, questionnaires were distributed to a representative sample of households with grid electricity. The latter criterion was of relevance because of the relative numbers of households without electricity. Households with different sizes, varied occupants (ranging in number, age, occupation and income) and different behavioural patterns (in terms of energy usage) were invited to give details of their electricity usage through a collation of appliances, ratings and their usage per week. This was developed and incorporated into Equation 2. In order to determine the relevance of data obtained from the questionnaire a comprehensive statistical analysis package (SPSS 19) was used to analyse the data collected. The results of which were used to determine electrical energy usage in households thereby informing the development of the proposed energy budget of Botswana.

Adapting the categorization used by Yao and Steemers (2005) and Hamidi et al (2009), domestic appliances collated from the survey were classed into different categories as illustrated in Fig. 5. It must be noted that this 
is collated from the most common of the electrical appliances that were surveyed. Therefore, this is by no means an exhaustive list.

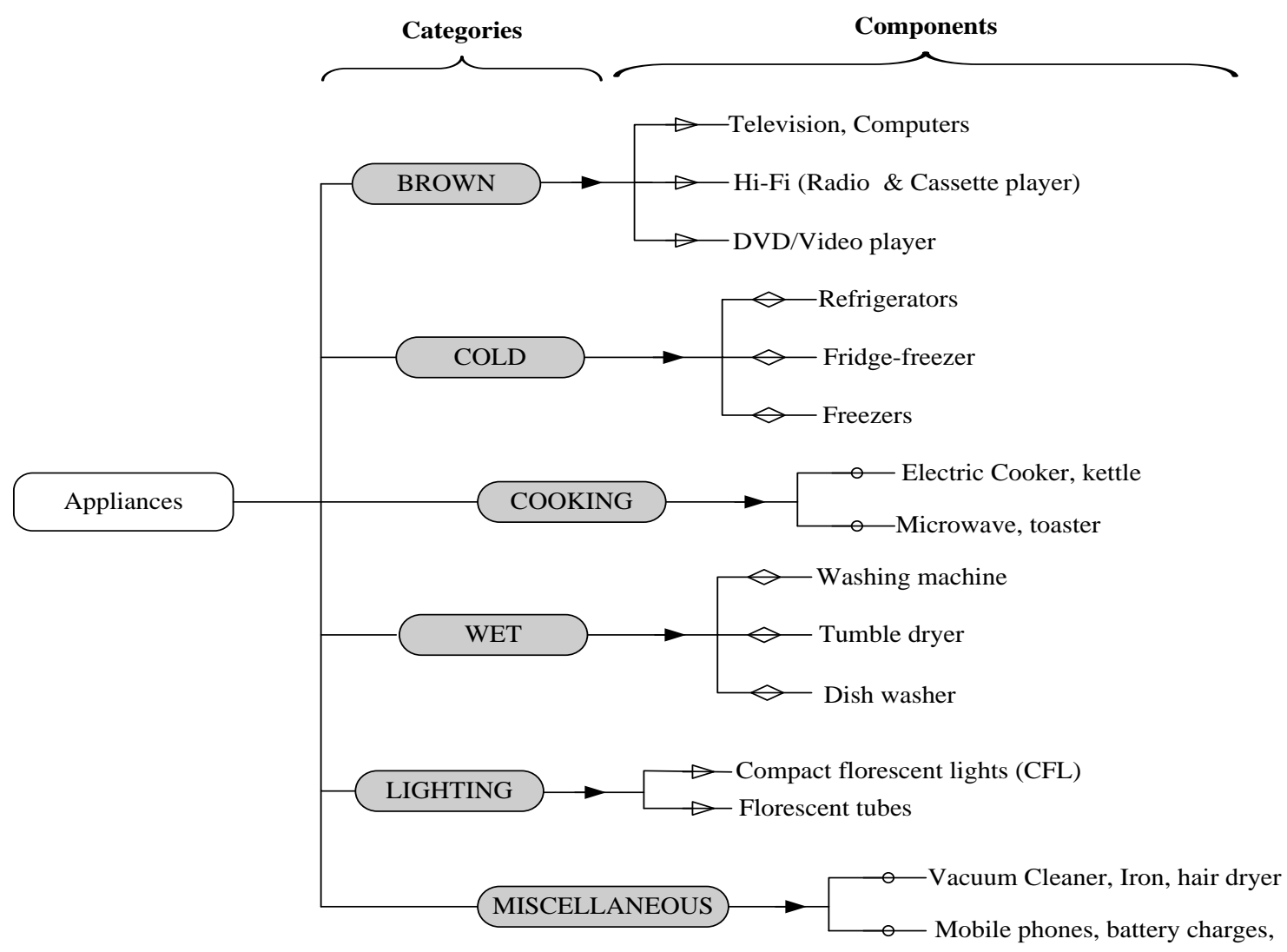

Fig. 5: Energy consumption equipment in surveyed households

Assumptions that were taken into consideration when computing the country's energy budget are as follows

- Weekend load profiles have been equalised to those for the workdays for simplicity that is a typical day was assumed for the whole week (Ihbal et al., 2011). This is because data collected was based on average weekly usages and daily usage was not investigated.

- Every household has one of each appliance except for phones and lighting bulbs (Ihbal et al., 2011)

- There are constant loads for cold appliances (e.g. refrigerator, combined fridge-freezer, freezer). Energy consumption of cold appliances depends on the number of times they are opened and shut (Firth et al., 2008; Ihbal et al., 2011).

- The week surveyed was assumed to be a typical week of a year.

- Efficiency of appliances was not taken into consideration 
These assumptions amongst others have been mentioned throughout the study to ensure a detailed understanding of how the data and results were obtained and analysed respectively.

\section{Analysis and Results}

A simplified relation between appliance, its rating and duration of use was developed to investigate the energy consumption per appliance per week. This relation is as illustrated in Equations 2.

$E_{e}=N_{a} \times A_{r} \times H_{u}$

Where:

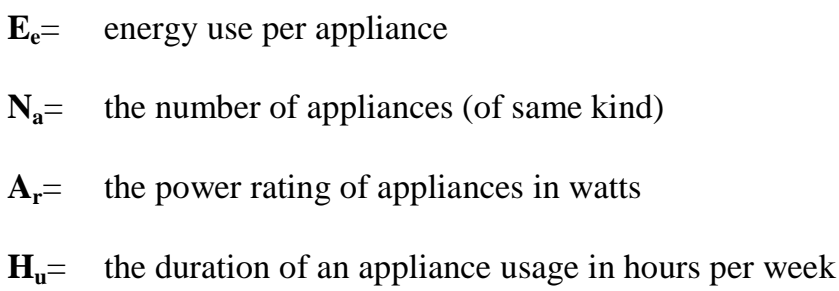

Equation 2 is applicable to all categories of domestic appliances but for cold appliances where this is not applicable because even though the appliances are in continuous use (i.e. switched on all the hours of the day) their compressors do not run continuously hence they do not draw a constant amount of power (Firth et al., 2008). In this regard a standard usage which complies with manufactures' data was used. While in other countries water boilers use gas, in Botswana water boilers (geysers) use electricity as the sole means of energy supply. As a result these are factored into the calculations as appliances with energy consumption estimates based on Equation 2. Cooling and space heating is usually done through air conditioning so where applicable this is also calculated. However, some households use fans (ceiling, table size or standing) for cooling and electric heaters for space heating, therefore these were also taken into consideration.

The results obtained for individual households were then used to calculate the energy demand of the entire domestic sector $\left(\mathrm{E}_{T D}\right)$ in the country using Equation 3. It must be noted that $\mathrm{E}_{\mathrm{TD}}$ is a combination of the grid and non-grid connected households (as expanded in Equation 8).

$$
E_{T D}=H_{h} \overline{E_{n}}+H_{m} \overline{E_{p}}+H_{l} \overline{E_{q}}
$$


Equations 4-6 expand on the energy used per income category $\left(\overline{E_{n}}, \overline{E_{p}}, \overline{E_{q}}\right)$, taking into account cold appliances. These equations assume a linear relationship between appliances and energy consumption. Due to the output response which statistically demonstrates a normal distribution, the assumption is that the average can be used to extrapolate the total country demand.

$$
\begin{aligned}
& \overline{E_{n}}=\frac{1}{n} \sum_{i=1}^{n} E_{i}=\frac{1}{n} \sum_{i=1}^{n}\left(E_{e_{i}}+E_{c_{i}}\right) \\
& \overline{E_{p}}=\frac{1}{p} \sum_{j=1}^{p} E_{j}=\frac{1}{p} \sum_{j=1}^{p}\left(E_{e_{j}}+E_{c_{j}}\right) \\
& \overline{E_{q}}=\frac{1}{q} \sum_{k=1}^{q} E_{k}=\frac{1}{q} \sum_{k=1}^{q}\left(E_{e_{k}}+E_{c_{k}}\right)
\end{aligned}
$$

Where

$$
\begin{aligned}
& \overline{E_{n}}, \overline{E_{p}}, \overline{E_{q}} \quad=\quad \text { average energy consumption of high, medium and low income households } \\
& \text { respectively in a year. } \\
& E_{T D} \quad=\quad \text { annual energy consumption of the entire domestic sector } \\
& i, j, k=\text { represents a unit household in high, medium and low income categories } \\
& H_{h}, H_{m} \text { and } H_{l}=\quad \text { total number of high, medium and low income households in Botswana }
\end{aligned}
$$

On average the overall projected electricity consumption as calculated from the questionnaire response (based on the statistical distribution) was $8949 \mathrm{kWh} \pm 2 \%, 5723 \mathrm{kWh} \pm 1 \%$ and $3102 \mathrm{kWh} \pm 2 \%$ for high, medium and low income categories respectively. Table 3 gives an overview of the household figures obtained from the statistic department (CSO, 2011) and average consumption values obtained from the survey. In this study it must be noted that the results does not provide household breakdown because household demography was solely dependent on the income classification provided by the statistical department as discussed in section 4. Using Equation 3 and data in Table 3, the total energy consumption $\left(E_{T D}\right)$ of the domestic sector for 2011 was calculated to be $2912 \mathrm{GWh}$ per year assuming $100 \%$ access to electricity. However, in 2011 overall electricity access was 43\%, increasing to 49\% in 2012 (Section 3.1). This aligns with Equations 8-10 where a significant percentage (in this case 57\% and 51\% of 2011 and 2012 respectively) is still non-grid connected. 
Table 3: Botswana energy consumption per income category

\begin{tabular}{lccc}
\hline & $\begin{array}{l}\text { Average electricity consumption } \\
\text { per household (kWh)* }\end{array}$ & Number of households** & $\begin{array}{l}\text { Total energy consumption } \\
\text { (GWh) }\end{array}$ \\
\hline High income & 8949 & 88,863 & 795 \\
Middle income & 5723 & 255,482 & 655 \\
Low income & 3102 & 211,050 & 2,912 \\
\hline Total & 17,774 & 555,395 & \\
\hline
\end{tabular}

* Calculations based on the 402 respondents

** Calculated using 2011 population and housing census figures (CSO, 2011)

While Equations 2 - 6 focus on the domestic sector, it would be noted that the energy budget of the whole country is made up of all four sectors of the economy. Therefore Equation 7 was used to compute the total energy $\left(\mathrm{E}_{\mathrm{T}}\right)$ requirements of the country.

$$
E_{T}=E_{T D}+E_{T M}+E_{T C}+E_{T G}
$$

Although households considered in this study were grid connected, $\mathrm{E}_{\mathrm{T}}$ is the total electricity output that includes both grid connected ( $\mathrm{gc}$ ) and non-grid connected (ngc) energy consumption. That is, assuming that energy is available to everyone in the country. The individual sectors of $\mathrm{E}_{\mathrm{T}}$ as in Equation 7 (i.e. $\mathrm{E}_{\mathrm{TD}}, \mathrm{E}_{\mathrm{TC}}$ and $\mathrm{E}_{\mathrm{TG}}$ ) are further elaborated to incorporate this subdivision (as shown in Equations 8-10). Practically, all households requiring the use of electricity should have similar profiles. However, in the case of Botswana, non-grid connected household do not have any access to electricity hence would not have a demand profile.

$$
\begin{aligned}
& E_{T D}=E_{T D(g c)}+E_{T D(n g c)} \\
& E_{T C}=E_{T C(g c)}+E_{T C(n g c)} \\
& E_{T G}=E_{T G(g c)}+E_{T G(n g c)}
\end{aligned}
$$

\section{Where}

$$
\begin{aligned}
& \boldsymbol{E}_{T D}=\text { the total energy for the domestic sector }(\mathrm{GWh}) \\
& \boldsymbol{E}_{\boldsymbol{T C}}=\text { the total energy for the commercial sector }(\mathrm{GWh})
\end{aligned}
$$


$\boldsymbol{E}_{\boldsymbol{T}}=$ the total energy for the government sector $(\mathrm{GWh})$

$\boldsymbol{E}_{T M}=$ the total energy for the mining sector $(\mathrm{GWh})$. This is always assumed to be grid connected

The 2912 GWh domestic sector energy consumption calculated above is at $100 \%$ energy access. Therefore energy consumption at $43 \%$ was calculated to be $1252 \mathrm{GWh}$ (see Table 4). The domestic energy consumption figure together with the percentage share by sector were then used to compute the energy consumption of each sector and hence the total consumption of the whole country at $43 \%$. These calculations were also carried out for 2012 (49\% access) where domestic consumption at $100 \%$ was 2929 GWh.

Considering the fact that the known values are that of the domestic sector (estimated from the survey) and the overall energy consumption for 2011 (i.e. $3118 \mathrm{GWh}$ ) and 2012 (i.e. $3198 \mathrm{GWh}$ ), estimates from the other sectors were calculated. The percentage of the sector consumption for the Mining, Commercial and Government in 2011 and 2012 were calculated with respect to the total consumption of 3118 GWh and 3198 GWh. Considering Table 1 and 2, it can be seen that all the energy available for supply is accounted for in the form of consumption. Therefore the results discussed in the section are based on the assumption that all the energy supplied is accounted for in the form of consumption and if calculated consumption is higher than supply should equate to it or be higher than it in order to meet the population requirements. 
Table 4: Average yearly energy consumption by sector

\begin{tabular}{|c|c|c|c|c|c|c|}
\hline \multirow{2}{*}{ SECTOR } & \multicolumn{3}{|c|}{2011} & \multicolumn{3}{|c|}{2012} \\
\hline & $\begin{array}{c}\text { Percentage } \\
\text { by Sector } \\
(\%) * *\end{array}$ & $\begin{array}{c}\text { Consumption } \\
\text { (GWh) }\end{array}$ & $\begin{array}{l}\text { Percentage } \\
\text { by Sector } \\
(\%)^{* * *}\end{array}$ & $\begin{array}{c}\text { Percentage } \\
\text { by Sector } \\
(\%)^{* *}\end{array}$ & $\begin{array}{c}\text { Consumption } \\
\text { (GWh) }\end{array}$ & $\begin{array}{c}\text { Percentage } \\
\text { by Sector } \\
(\%) * * * \\
\end{array}$ \\
\hline Domestic & 28.0 & 1252 & 35.8 & 27.5 & 1289 & 35.7 \\
\hline Mining & 35.8 & 1116 & 31.9 & 34.0 & 1087 & 30.1 \\
\hline Commercial & 26.3 & 820 & 23.4 & 28.5 & 911 & 25.3 \\
\hline Government* & 9.9 & 309 & 8.8 & 10.0 & 320 & 8.9 \\
\hline \multicolumn{7}{|l|}{ Total } \\
\hline Percentage & 100 & & 100 & 100 & & 100 \\
\hline
\end{tabular}

Energy Consumption

(calculated)

3497

3607

Energy Consumption

$\left(\mathrm{BPC}^{* *}\right)$

3118

3198

*This sector is as stated in documentation and yet to be clearly defined.

**Available figures from BPC (BPC, 2012)

$* * *$ Re-calculated percentages from the study

From Table 4, the annual energy consumption for 2011 (3497 GWh) was calculated to be approximately $12 \%$ more than what the country is quoting. Consequently, energy that should have been available for supply to meet the country's consumption for 2011 was calculated to be $12 \%$ higher than what is being quoted. Considering BPC values for 2012 (Table 2), energy consumption increased by 2.5\% (approximately) from the 2011 consumption. Taking this into consideration and assuming a linear increase, energy consumption for 2012 was calculated to be $13 \%$ (3607 GWh) more than what is stipulated by the country (3198 GWh). Energy supply was therefore $13 \%$ more than what is being stipulated.

From this table it is obvious that the energy by sector percentage share does not stay the same. Considering the BPC data, the domestic sector is underreported / underestimated as the percentage share of electricity use changes. This is evident from the re-calculated percentages. The variation in quoted (BPC, 2012) and calculated percentages, illustrates the possible boundaries and the level of detail that can be achieved based on the statistical assumptions in this paper. This approach captures the measured consumption as given in Table 2 by taking into account the proportional mix of income types and sectors. 
The required operational capacity calculated from 2011 values that would generate enough energy to meet the country's estimated energy demand (from Table 4) is $\mathbf{4 0 0}$ MW assuming 80\% plant efficiency. Retrospectively, the capacity required for 2012 either imported or generated locally or both were higher than 2011 values that is, approximately 412 MW. Notably, the generation capacity from the 2011 and 2012 supply values quoted by BPC (2012) turns out to be between 350 - 370 MW. These values are significantly low compared to what is required to meet the country's needs, hence this may be a reason for the constant blackouts.

Botswana proposed to build Morupule B power station (see Section 2.3) in efforts to meet the country's demand and to export excess power. Although, this is encouraging the results of this paper indicate that the extra 1200 MW capacity would only meet the country's demand if work was completed in 2011 . In 2012 and beyond, the increasing consumption requires a corresponding increase in installed capacity that would meet consumption and possible $100 \%$ access.

In light of this, it is interesting that access to electricity in Botswana is currently quoted at $49 \%$ because from this research, access is currently between $38-39 \%$. On a different note energy access is different from household access as mentioned in Section 1. Therefore the higher value quoted by BPC may be due to considering energy access in isolation from household access. However, considering these discrepancies, it is anticipated that knowing the trend in domestic energy consumption would give a better understanding of the total energy required by the country to meet its needs.

\section{Conclusions}

This research has demonstrated the significance of investigating current trends in electricity generation, accessibility and consumption in Botswana. Within the context of this study, due to the lack of depth in documentation, significant assumptions were made to understand the limitations and calculations of the results.

It is evident from this paper that, the Morupule A power station does not meet the country's electricity demand. Though it is anticipated that the commissioning of Morupule B power station (which is still behind schedule), would increase the percentage figures of electricity accessibility, the actual figures continue to be debatable as it remains unknown. The generation capacity for 2011 and 2012 as quoted by BPC (BPC, 201; BPC, 2012) turns out to be between 350 - $370 \mathrm{MW}, 11 \%$ and $14 \%$ less than estimated values of $400-412 \mathrm{MW}$. 
Though access to electricity was quoted as 43 and 49\% for 2011 and 2012 respectively, from this research access is significantly low, with estimated values calculated to be $38 \%$ and $39 \%$ respectively.

The results presented in this paper provide an insight into the potential demand for electricity in relation to the trend of the growing consumption. This investigation, through the analysis and results has shown that, the best approach to improve the electricity accessibility and energy security is to increase the percentage of supply (i.e local generation and/or imports).

It must be noted that, other aspects, such as the effects of social impacts have not been considered in this research but are worth noting as a significant parameter for further studies.

\section{Acknowledgment}

The authors would like to appreciate the support from the Visiting Fellow Grant funded by the Key Laboratory of the Three Gorges Reservoir Region's Eco-Environment, Ministry of Education at Chongqing University, China. Thanks to the Department of Tertiary Education and Financing at the Botswana Ministry of skills and development, without whom this work would not have been possible

\section{References}

Ang, J.B. (2008). Economic development, pollutant emissions and energy consumption in Malaysia. Policy modelling, 30 (2), 271-278.

Apergis, N. and Payne, J. E. (2009). Energy consumption and economic growth in Central America: Evidence from a panel cointegration and error correction model. Energy economics, 31(2), 211-216.

Asenjoenergy (2008). Map of Botswana indicating Morupule colliery and its neighbouring countries. Available at: www.asenjoenergy.com/projectareas_value-proposition.asp. [Cited 10 June 2013].

Bhattacharyya, S. C. and Timilsina, G. R. (2010). Modelling energy demand of developing countries: Are the specific features captured. Energy policy, 38(4), 1979-1990.

BHC- Botswana Housing Corporation (2009). Property rental: Guidelines Policies Requirements. Available at: http://www.bhc.bw/Guidelines_Policies_Requirements.html. [Cited 05 April 2013].

BPC- Botswana Power Corporation (2010). Annual report 2010. http://www.bpc.bw/Pages/annual_report.aspx. [Cited 15 May 2013]. 
BPC -Botswana Power Corporation (2011). Annual report 2011. http://www.bpc.bw/Pages/annual_report.aspx.

[Cited 15 May 2013].

BPC- Botswana Power Corporation (2012). Annual report 2012. http://www.bpc.bw/Pages/annual_report.aspx .

[Cited 09 May 2013].

Brew-Hammond, A. (2010). Energy access in Africa: Challenges ahead. Energy Policy, 38(5), 2291-2301.

CSO- Central Statistics Office (2010). Botswana Statistical Year Book Available at:

http://www.cso.gov.bw/templates/cso/file/File/Botswana\%20Statistical\%20Year\%20Book\%202010.PDF.

[Cited 10 June 2013].

CSO- Central Statistics Office (2011). 2011 population and housing census: preliminary results brief.

http://www.cso.gov.bw/templates/cso/file/File/Census\%202011\%20Preliminary\%20\%20Brief\%20Sept\%20 29\%202011.pdf [Cited 25 May 2013].

Chen, S., Li, N., Guan, J., Xie, Y., Sun, F. and Ni, J., 2008. A statistical method to investigate national energy consumption in the residential building sector of China. Energy and buildings, 40 (4), 654-665.

Ihbal, A. M., Rajamani, R. A., Abd-Alhameed, R. A. and Jalboub, M. K., 2011. Statistical predictions of electric load profiles in the UK domestic buildings. Iraq Journal of electrical and electronic engineering, 7 (2), 151 156.

Eskom (2011). Eskom annual report. Available at: http://www.eskom.co.za/c/84/annual-report/. [Cited 15 July 2013].

Fagbenle, R. (2001). National renewable energy policy objectives and programmes in Botswana. Renewable Energy, 24 (3-4), 419-437.

Firth, S., Lomas, K., Wright, A., and Wall, R. (2008). Identifying trends in the use of domestic appliances from household electricity consumption measurements. Energy and Buildings, 40(5), 926-936.

Hamidi, V., Li, F. and Robinson, F. (2009). Demand response in the UK's domestic sector. Electric power system research, 79 (12), 1722-1726.

Howells, M., Alfstad, T., Victor, D., Goldstein, G., Remme, U., 2005. A model of household energy services in a low-income rural African village. Energy Policy, 33 (14), 1833-1851.

IEA, 2006. World Energy Outlook, International Energy Agency, Paris. Available at: http://www.worldenergyoutlook.org/media/weowebsite/2008-1994/WEO2006.pdf. [Cited 12 March 2013].

IEA, 2012. World Energy Outlook, International Energy Agency, Paris. Available at http://www.polsci.chula.ac.th/pitch/ep13/weo12.pdf. [Cited 11 November 2013] 
Kanagawa, M. and Nakata, T. (2008). Assessment of access to electricity on the socio-economic impacts in rural areas of developing countries. Energy policy, 36 (6), 2016-2029.

Kaygusuz, K. (2012). Energy for sustainable development: A case of developing countries. Renewable and sustainable energy reviews, 16 (2), 1116-1126.

Kraft, J. and Kraft, A. (1978). On the relationship between energy and GNP. Journal of Energy and Development, 3(2), 401-403.

Mguni, M. and Benza, B. (2013). Government sue over Morupule B delays. MMegionline, [online] 8 March. Available at: http://www.mmegi.bw/index.php?sid=4\&aid=1662\&dir=2013/March/Friday8. [Cited 12 March 2013].

Mining-technology (2012). Morupule Colliery Expansion Project, Botswana. Available at: http://www.miningtechnology.com/projects/morupule-colliery-expansion-project/. [Cited 12 March 2013].

National energy policy for Botswana (Final Draft) - Technical Report (2010). Avaialable at: http://pdf.usaid.gov/pdf_docs/PNADU385.pdf . [Cited: 24 November 2011]

Navani, J. P., Sharma, N. K. and Sapra, S. (2003). Technical and non-technical losses in power system and its economic consequences in Indian economy. International journal of electronics and computer engineering, 1(2), 757-761.

Ofetotse, E. L. and Essah, E. A. (2012). Energy overview of Botswana: Generation and Consumption. Proceedings of the West Africa Built Environment Research (WABER) Conference, 24-26 July 2012, Abuja, Nigeria, 1011-1021.

Ouedraogo, N. S. (2013). Energy consumption and economic growth: Evidence from the economic community of West African States (ECOWAS). Energy economics, 36, 637-647.

Saidur. R., Masjuki, H. H. and Jamaluddin, M. Y. (2007). An application of energy and exergy analysis in domestic sector of Malaysia. Energy Policy, 35(2), 1050-1063.

Smith, T. B. (2004). Electricity theft: a comparative analysis. Energy policy, 32, 2067-2076.

Swan, L. G. and Ugursal, V. I. (2009). Modelling of end-use energy consumption in the domestic sector: a review of modelling techniques. Renewable and sustainable energy reviews, 13(8), 1819-1835.

Widén, J. and Wäckelgård, E., 2010. A high-resolution stochastic model of domestic activity patterns and electricity demand. Applied Energy, 87 (6), 1880-1892.

Winkler, H., Simoes, A. F., La Rovere, E. L., Alam, M., Rahman, A., Mwakasonda, S. (2011). Access and affordability of electricity in developing countries. World development, 39 (6), 1037-1050. 
Yao, R. and Steemers, K. (2005). A method of formulating energy load profile for domestic buildings in the UK. Energy and buildings, 37 (7), 663-671.

Yohanis, Y. G., Mondol, J. D., Wright, A. and Norton, B.. 2008. Real-life energy use in the UK: How occupancy and dwelling characteristics affect domestic electricity use. Energy and building, 40 (6), 10531059.

Yu, E.S.H. and Choi, J.Y. (1985). The causal relationship between energy and GNP: an international comparison. Journal of Energy and Development, 10(2), 249-272. 